Article

\title{
High-Fidelity Battery Model for Model Predictive Control Implemented into a Plug-In Hybrid Electric Vehicle
}

\author{
Nicolas Sockeel ${ }^{1, *}$, Masood Shahverdi ${ }^{2}$, Michael Mazzola ${ }^{1}$ and William Meadows ${ }^{1}$ \\ 1 Center for Advanced Vehicular Systems and Electrical and Computer Engineering Department, \\ Mississippi State University, Starkville, MS 39759, USA; \\ mazzola@ece.msstate.edu (M.M.); meadows@cavs.msstate.edu (W.M.) \\ 2 Electrical and Computer Engineering Department, California State University, Los Angeles, CA 90032, USA; \\ mshahve3@calstatela.edu \\ * Correspondence: nrs192@msstate.edu; Tel.: +1-662-341-6393; Fax: +1-662-325-5433
}

Academic Editor: Juan Carlos Álvarez Antón

Received: 30 August 2016; Accepted: 12 March 2017; Published: 6 April 2017

\begin{abstract}
Power management strategies have impacts on fuel economy, greenhouse gasses (GHG) emission, as well as effects on the durability of power-train components. This is why different off-line and real-time optimal control approaches are being developed. However, real-time control seems to be more attractive than off-line control because it can be directly implemented for managing power and energy flows inside an actual vehicle. One interesting illustration of these power management strategies is the model predictive control (MPC) based algorithm. Inside a MPC, a cost function is optimized while system constraints are validated in real time. The MPC algorithm relies on dynamic models of the vehicle and the battery. The complexity and accuracy of the battery model are usually neglected to benefit the development of new cost functions or better MPC algorithms. The contribution of this manuscript consists of developing and evaluating a high-fidelity battery model of a plug-in hybrid electric vehicle (PHEV) that has been used for MPC. Via empirical work and simulation, the impact of a high-fidelity battery model has been evaluated and compared to a simpler model in the context of MPC. It is proven that the new battery model reduces the absolute voltage, state of charge $(\mathrm{SoC})$, and battery power loss error by a factor of 3.2, 1.9 and 2.1 on average respectively, compared to the simpler battery model.
\end{abstract}

Keywords: vehicle and battery modeling; model predictive control (MPC) application; plug-in hybrid electric vehicle (PHEV) application

\section{Introduction}

To reduce fuel consumption, greenhouse gasses (GHG) emission or to improve battery lifetime, advanced power management strategies have been studied [1,2]. To achieve these goals, different off-line and real-time optimal control approaches are being developed. Model predictive control (MPC, see Figure 1 [3]) is a promising example. MPC is an advanced control methodology that was originally used in the process industries for power plants and oil refineries since the 1980s $[4,5]$. MPC is capable of predicting future events, in a finite-horizon, and is able to take controlled actions to optimize a cost function. Proportional, integrator, and derivative (PID) and linear quadratic regulator (LQR) controllers do not have this predictive ability. However, the prediction of MPC is usually computed for a relatively short time horizon in the future due to its computational cost. In recent years, MPC has been used for hybrid electric vehicle (HEV) and plug-in HEV (PHEV) applications, as shown in the comprehensive survey of power management topics [6]. In [6], dynamic programming-based 
strategies are introduced as the most conventional off-line approaches while MPC-based algorithms, and equivalent fuel consumption minimization strategy (ECMS)-based [7-9] are defined as the primary on-line methods. The former has been of interest in many works. For example, using a MPC, an overall power efficiency is maximized, instead of fuel consumption minimization, for a series HEV [10]. In [11], based on the price of gas and electricity in the United States, a MPC minimizes the cost of the vehicle's energy use for a series PHEV. In another research report, engine transient characteristic is incorporated in a MPC for parallel HEV [12]. In other publications [13,14], the goal of MPC is to reduce the $\mathrm{CO}_{2}$ emissions. To implement a fast MPC, the authors in [14] proposed to compute the entire control law off-line. A global optimization-based MPC is developed, and experimental validation is provided on the test bench in [15]. Stochastic MPC with learning is proposed and validated by simulation in [16]. The MPC-based control strategy is also applied to solve the energy management problem of a series [9,17] and power-split HEVs in [18] and to analyze the potential benefits of integrating ultracapacitors (UC) in the energy storage system (ESS) unit of a power-split HEV in [19-22]. Using the Pontryagin's minimum principle (PMP), the MPC of fuel cell hybrid vehicles (FCHVs) optimizes battery lifetime while reducing battery energy loss, fuel consumption, and powertrain cost in [23,24].

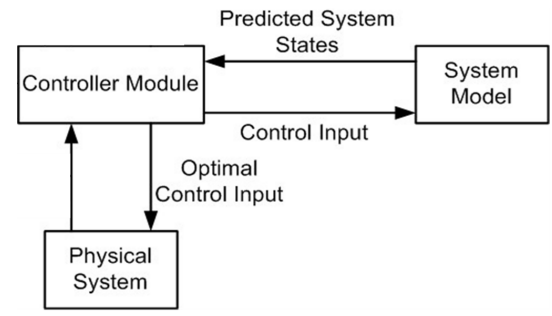

Figure 1. Block diagram of a model predictive control (MPC) controller [3].

MPC relies on dynamic models of the vehicle, most often linear empirical models obtained by system identification [25]. In the references cited above, the significance of a MPC controller for HEV applications has been highlighted. In this literature review, the authors mainly focus on the influence of a new cost function, but they do not deal with the benefit of a high accuracy battery model. Their models are far simpler than the one introduced in papers [26-28] for automotive applications. For instance, their impedance battery model is limited to an internal resistance impedance model, as shown in Figure 2. Developing a high-fidelity battery model for a HEV is a key opportunity to improve the global performance of a MPC. This is why the main contribution of this manuscript is developing and evaluating a high-fidelity battery model of a PHEV that has been used for a MPC. In Section 2 of this paper, a Matlab model based on a real PHEV is presented. It provides an overview of the PHEV model and helps to understand the role of the battery model. Then, Section 3 is entirely devoted to the description of the high accuracy battery model for a MPC. It precisely simulates the battery voltage response through one resistance in series with a two resistances/capacitors (RC) network, and replicates the battery aging phenomenon. Finally, in Section 4, the impact of the high-fidelity battery model has been evaluated through empirical work and simulation and compared to the simple internal resistance battery model in the context of MPC.

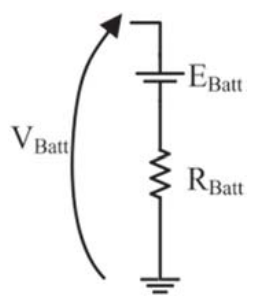

Figure 2. Equivalent battery model for MPC controller design [18]. 


\section{Vehicle Model}

In this section, the architecture of the reference car is shown in Figure 3. It provides an overview of the vehicle model and helps to understand the role of the battery model. The vehicle is a series PHEV. The arrows in Figure 3 indicate the possible direction of the energy flow inside the power-train. An electric generator, an ESS composed of a lithium-ion battery, and an electric motor are connected to a DC bus. During acceleration, the generator or the ESS provide power to the DC bus for the motor while, during regenerative braking, the motor works as a generator and provides power to the ESS through the DC bus. Except for cranking the engine at the very start of a drive, there is no energy transfer from the battery to the engine through the generator while the car is running. Consequently, the energy flow in this situation is minimal and considered as negligible compared to the total energy consumption. This is why the arrows between engine and generator, and between generator and battery are uni-directional. Table 1 summarizes the specifications of the power-train components. The size of the ESS has been selected based on a parametric study on the available size of high energy density modules from A123 (Livona, MI, USA) to minimize fuel consumption [26]. High energy density modules are preferred to high power density modules because the ESS of a PHEV is usually sufficient to meet the power requirements of the vehicle power-train. Therefore, the ESS should be able to store more energy to increase the all-electric range and, as a result, to reduce the fuel consumption of the vehicle. However, the available space inside the concept vehicle test platform (Subaru BRZ 2015) constrains the maximum ESS size. The size of the engine has been selected based on the reduced size engine concept to achieve maximal fuel economy as explained in [29]. A motor unit power has been chosen to keep the acceleration performance of this new PHEV close to its original performance. The unit includes two independent motors for both rear wheels.

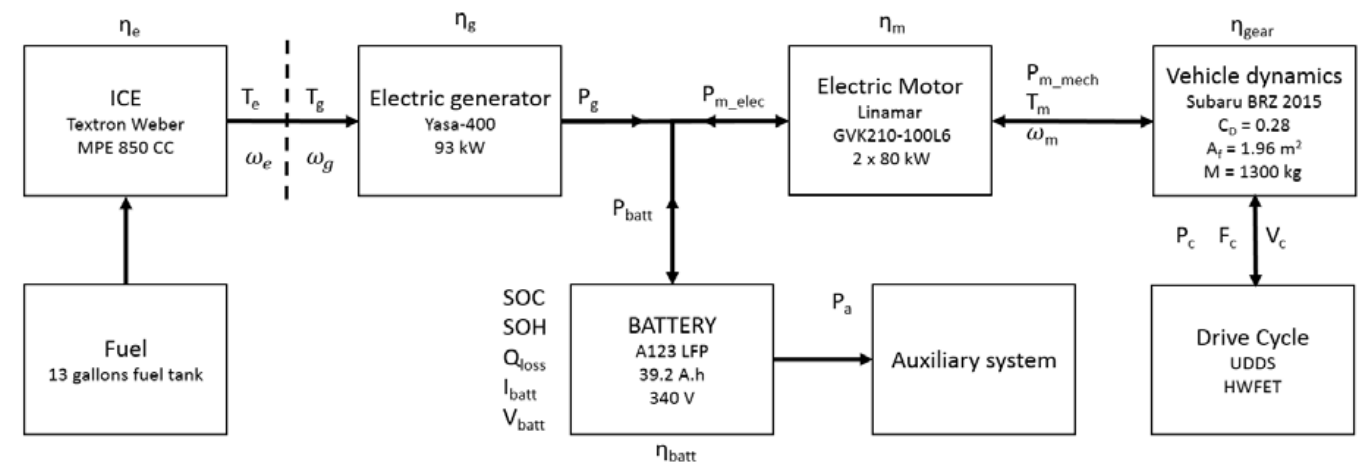

Figure 3. Series hybrid electric vehicle (HEV) block diagram of the Subaru BRZ 2015. ICE: internal combustion engine; SoC: state of charge; $\mathrm{SOH}$ : state of health; LFP: lithium iron phosphate $\left(\mathrm{LiFePO}_{4}\right)$; UDDS: urban dynamometer driving schedule; and HWFET: highway fuel economy test.

The characteristics of the vehicle model are given in Table 1 and Figure 3. The equations describing the vehicle dynamics, the electric motor and generator, and the engine are included in the Appendix A.

Table 1. Specification of power-train components. ESS: energy storage system; and PHEV: plug-in hybrid electric vehicle.

\begin{tabular}{ccc}
\hline Power-Train Component & Name & Characteristics \\
\hline ESS & LFP prismatic cells from A123 & $\begin{array}{c}\text { Capacity }=39.2 \mathrm{Ah} ; \text { nominal voltage }=340 \mathrm{~V} ; \\
\text { nominal energy }=13.3 \mathrm{kWh} \text { c configuration: } 7 \times 15 \mathrm{~s} 2 \mathrm{p} .\end{array}$ \\
\hline Engine & Model MPE850 from Weber & $41 \mathrm{~kW}, 2$ cylinders, 850 cc. \\
\hline Generator & Model YASA-400 & $93 \mathrm{~kW}$, axial flux permanent magnet. \\
\hline Motors Unit & Model GVK210-100L6 from Linamar & $2 \times 80 \mathrm{~kW}$, unit ratio $=8.49$. \\
\hline Vehicle dynamics & 2015 Subaru BRZ Limited & $\begin{array}{c}\text { Drag coefficient }=0.28 ; \text { frontal area }=1.9695 \mathrm{~m}^{2} ; \\
\text { PHEV mass }=1300 \mathrm{~kg} ; \text { wheel radius }=0.3 \mathrm{~m} .\end{array}$ \\
\hline
\end{tabular}




\section{Battery}

\subsection{Impedance}

To capture the battery dynamic accurately, an internal series resistance and a two RC network, as shown in Figure 4, are commonly used to design battery impedance for EV and HEV applications [30-32]. The value of each resistance and capacity are based on [28,33]. Indeed, the battery used in the vehicle is the same as the one used in [28,33]: $\mathrm{A} 123 \mathrm{LiFePO}_{4}$ prismatic module with its own battery management system (BMS). Only the configuration changes: from $5 \times 22 s 3 p$ in $[28,33]$ to $7 \times 15 s 2 p$ in the Subaru BRZ 2015. Table 2 summarizes the characteristics of the battery impedance obtained at laboratory ambient temperature.

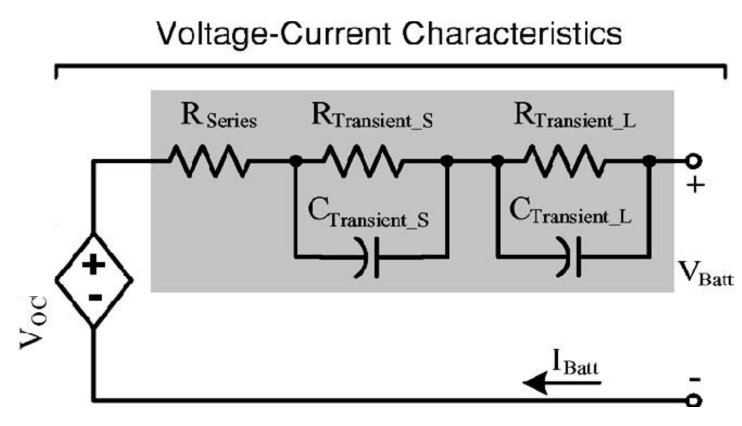

Figure 4. Impedance model of the battery [32].

Table 2. Characteristic of the battery impedance.

\begin{tabular}{ccc}
\hline Name & Value & Unit \\
\hline$R_{\text {Series }}$ & 0.1094 & $\operatorname{Ohm~}(\Omega)$ \\
\hline$R_{\text {Transient_S }}$ & 0.1111 & $\operatorname{Ohm~}(\Omega)$ \\
\hline$C_{\text {Transient_S }}$ & 0.4227 & kilo Farrad $(\mathrm{kF})$ \\
\hline$R_{\text {Transient_L }}$ & 0.1115 & $\operatorname{Ohm~}(\Omega)$ \\
\hline$C_{\text {Transient_L }}$ & 10.196 & kilo Farrad $(\mathrm{kF})$ \\
\hline
\end{tabular}

\subsection{Power, Voltage and Current}

The power provided or received by the battery is computed as follows:

$$
P_{\text {batt }}(\mathrm{t})= \begin{cases}\eta_{\text {batt }}\left[P_{\mathrm{m} \_ \text {elec }}(t)-P_{\mathrm{g} \_ \text {elec }}(t)+\mathrm{P}_{\mathrm{a}}\right] & \text { if }\left[P_{\mathrm{m}_{-} \text {elec }}(t)-P_{\mathrm{g} \_ \text {elec }}(t)+P_{\mathrm{a}}\right]<0 \\ \frac{\left[P_{\mathrm{m} \_ \text {elec }}(t)-P_{\mathrm{g} \_ \text {elec }}(t)+P_{\mathrm{a}}\right]}{\eta_{\text {batt }}} & \text { if }\left[P_{\mathrm{m}_{\_} \text {elec }}(t)-P_{\mathrm{g} \_ \text {elec }}(t)+P_{\mathrm{a}}\right] \geq 0\end{cases}
$$

In Equations (1) and (2), the battery is charging when $P_{\text {batt }}$ is negative and is discharging when $P_{\text {batt }}$ is positive. The battery current is then computed as follows:

$$
I_{\text {batt }}(t)=\frac{P_{\text {batt }}(t)}{V_{\text {batt }}(t-1)}
$$

Then, new voltage is computed using the impedance model of the battery in a discrete time domain as follows:

$$
V_{\text {Transient_S }}(t)=V_{\text {Transient_S }}(t-1)\left[1-\frac{1}{R_{\text {Transient_S }} C_{\text {Transient_S }}}\right]-\frac{I_{\text {batt }}(t-1)}{C_{\text {Transient_ }} \mathrm{S}}
$$




$$
\begin{aligned}
V_{\text {Transient_L }}(t) & =V_{\text {Transient_L }}(t-1)\left[1-\frac{1}{R_{\text {Transient_L }} C_{\text {Transient_L }}}\right]-\frac{I_{\text {batt }}(t-1)}{C_{\text {Transient_L }}} \\
V_{\text {batt }}(t) & =V_{\text {OC }}(t)-R_{\text {Series }} I_{\text {batt }}(t)+V_{\text {Transient_S }}(t)+V_{\text {Transient_L }}(t)
\end{aligned}
$$

The open circuit voltage of the battery, $V_{\mathrm{OC}}$, is an eight-order polynomial equation varying over state of charge $(S o C)$ representing the $S o C-V_{\mathrm{OC}}$ curve shown in Figure 5. The data and polynomial order are extracted from [34].

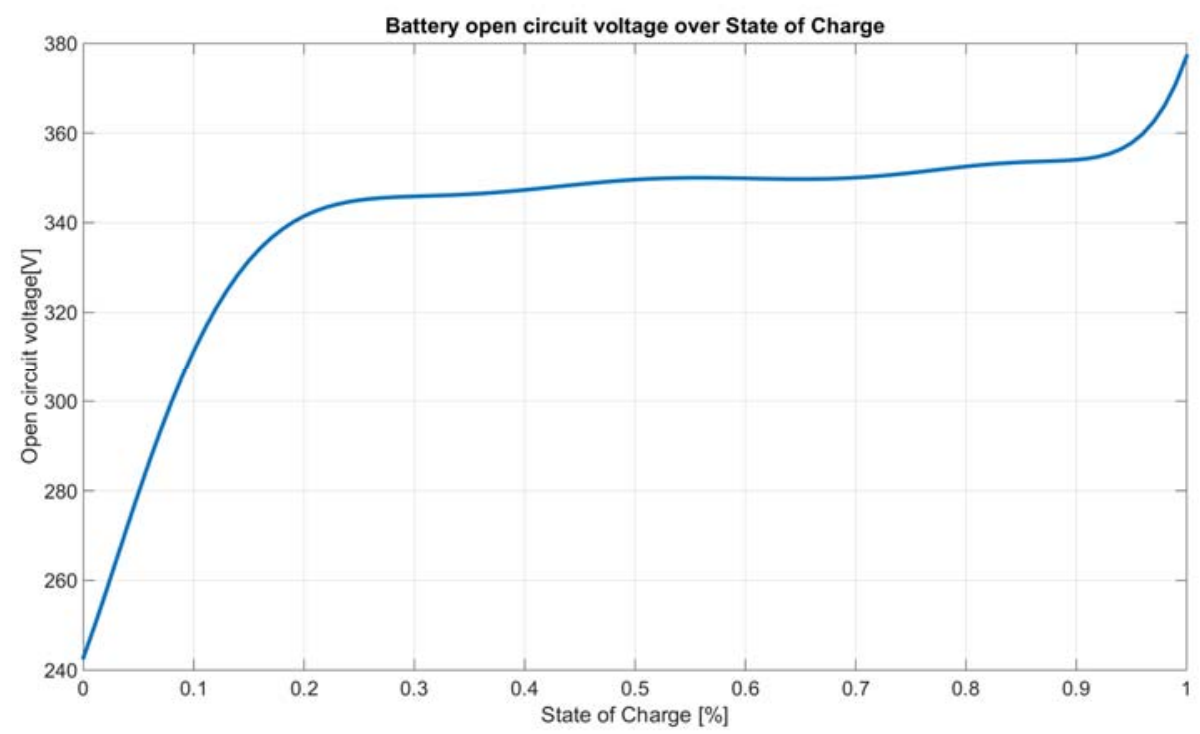

Figure 5. Open circuit voltage over battery SoC.

Here, it is noted that $I_{\text {batt }}(t)$ is computed by using $V_{\text {batt }}(t-1)$ whereas, in theory, $V_{\text {batt }}(t)$ is necessary. It is carried out this way because, at this stage, $V_{\text {batt }}(t)$ is unknown. The error induced by this approximation should be small considering that the voltage fluctuates slowly. However, this error exists and a simple recursive algorithmic method has been developed to minimize it. Indeed, once $V_{\text {batt }}(t)$ is computed by Equations (4)-(6), it is possible to recompute the value of $I_{\text {batt }}(t)$ using Equation (3) by replacing $V_{\text {batt }}(t-1)$ with $V_{\text {batt }}(t)$. Then, a new value of $V_{\text {batt }}(t)$ is also recomputed using Equation (4)-(6) again. Then, the same set of instructions can be repeated as many times as desired. The purpose of this algorithm is to reduce the error due to the approximation implied by Equation (3). This recursive algorithm only stops when $\frac{\left|P_{\text {batt }}(t)-I_{\text {batt }}(t) V_{\text {batt }}(t)\right|}{\left|P_{\text {batt }}(t)\right|} \leq \varepsilon$ with $\varepsilon$ a value as small as wanted. Figure 6 summarizes the current and voltage computation recursive algorithm.

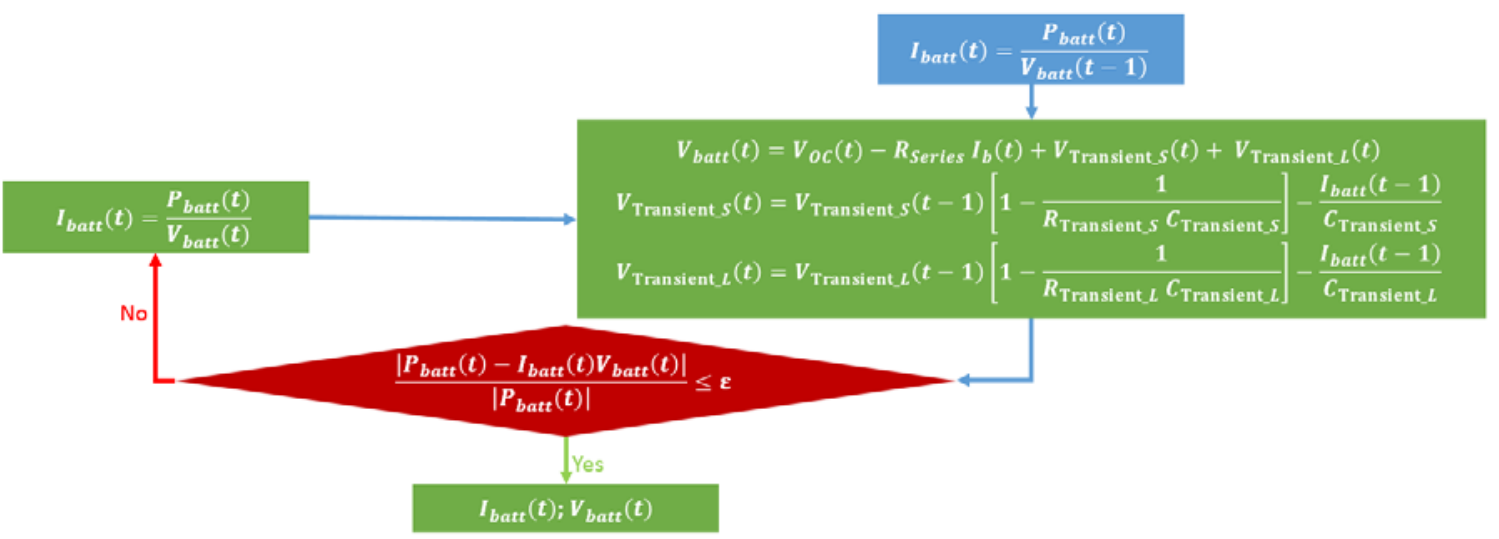

Figure 6. Current and voltage computation algorithm. 


\subsection{State of Charge}

The $S o C$ of the battery is computed by the coulomb counting Equation (7) in the discrete time domain.

$$
\operatorname{SOC}(t+1)=\operatorname{SOC}(t)-\frac{I_{\mathrm{batt}}(t) \Delta t}{3600\left(1-Q_{\text {loss }}(t)\right) C_{\mathrm{batt}}}
$$

\subsection{State of Health}

The battery state of health $(\mathrm{SoH})$ is represented by the capacity fade of the battery over cycling. Equations (8)-(13) simulate this phenomenon as a function of the cumulative SoC variation, C-rate, and temperature. Those formulas are extracted from [34] because their tested batteries have the same chemistry and come from the same manufacturer as the battery used in this work, which is the A123 $\mathrm{LiFePO}_{4}$ battery. This is why it is assumed that the aging characteristic of the large-format battery pack is similar to the cells tested in [35] despite the fact that the battery pack is composed of seven modules of 15 prismatic cells in series and two in parallel and not one cylindrical cell. For example, this assumption was accepted as a correct battery aging model for a causal optimal control-based energy management strategy for a parallel HEV using a lithium ion battery pack in [35]. The following equations explain how the $\mathrm{SoH}$ is computed in a discrete domain time.

$$
\begin{gathered}
Q_{\text {loss }}(t)=B(t) \exp \left(\frac{E_{\mathrm{a}}(t)}{R T_{\text {bat }}(t)}\right)(\Delta S O C(t))^{z} \\
\Delta S O C(t+1)=\Delta S O C(t)+|S O C(t+1)-S O C(t)| \\
B(t)=\mathrm{f}\left(C_{\text {rate }}(t)\right) \\
E_{\mathrm{a}}(\mathrm{t})=-31700+370.3 C_{\text {rate }}(t) \\
C_{\text {rate }}(t)=\frac{\left|I_{\text {batt }}(t)\right|}{C_{\text {batt }}}
\end{gathered}
$$

According to Table 3 of Wang's paper [34], Equation (8) should normally be written this way:

$$
\begin{gathered}
Q_{\text {loss }}(t)=B(t) \exp \left(\frac{E_{\mathrm{a}}(\mathrm{t})}{\mathrm{R} T_{\mathrm{bat}}(\mathrm{t})}\right)\left(A_{\mathrm{h}}\right)^{z} \\
A_{\mathrm{h}}=\text { cycle number } \times D O D \times 2
\end{gathered}
$$

Also, according to Equations (3) and (7) of the same paper [34], Equation (11) can be written and $z$ is equal to 0.55 . Moreover, $\mathrm{B}$ values are a function of $C_{\text {rate, }}$, defined as the ratio of the absolute value of the current to the cell capacity (Equation (12)). Wang's paper [34] only provides B values for four different $C_{\text {rate }}: C / 2,2 C, 6 C$, and 10C. In this paper, by default, the B value is linearly interpolated in function of $C_{\text {rate }}$ using data provided in Table 3 in [34], which leads to Equation (10).

By Equation (14) provided in Table 3 in [34], $A_{\mathrm{h}}$ is defined as a $S o C$ variation. Indeed, the SoC variation of a battery can be concluded with the following Equation (15):

$$
\triangle S O C=2 \times \text { cycle number } \times D O D=A_{\mathrm{h}}
$$

Since this battery is managed by its own BMS, which includes cells balancing, it allows us to hypothesize the following: the aging of battery cells should be roughly homogenous throughout the pack. From this hypothesis, it can be concluded that two of the same batteries, with different capacity, subjected to the same charge and discharge conditions (C-rate, temperature, number of cycles, depth of discharge (DOD), etc.) should be impacted the same way by the capacity fade. In other words, the results published in paper [34] would have been the same if they tested cells with different capacity but with the same chemistry $\left(\mathrm{LiFePO}_{4}\right)$ and manufacturer (A123). 


\section{Model Validation}

On the dynamometer, the vehicle has been driven over an HWFET drive cycle from full battery charge $(96 \%$ of $S o C)$ to its complete depletion $(5 \%$ of $S o C)$. The goal of this test was to validate the accuracy of the battery model. This is why, during this experiment, the engine and electric generator was not used. The effects of the road slope and the wind speed have not been considered, and so those parameters have been set to zero. The air density has been set to a constant value. At the time of the test, the coolant system, supposed to keep the battery temperature optimal, was not present. However, the internal BMS of the $\mathrm{A} 123 \mathrm{LiFePO}_{4}$ prismatic module records the temperature of the battery and provides an alarm response when it goes over the limits. During the experiment, it goes from $25^{\circ} \mathrm{C}$ to $38.5^{\circ} \mathrm{C}$. Figure 7 summarizes the experiment.

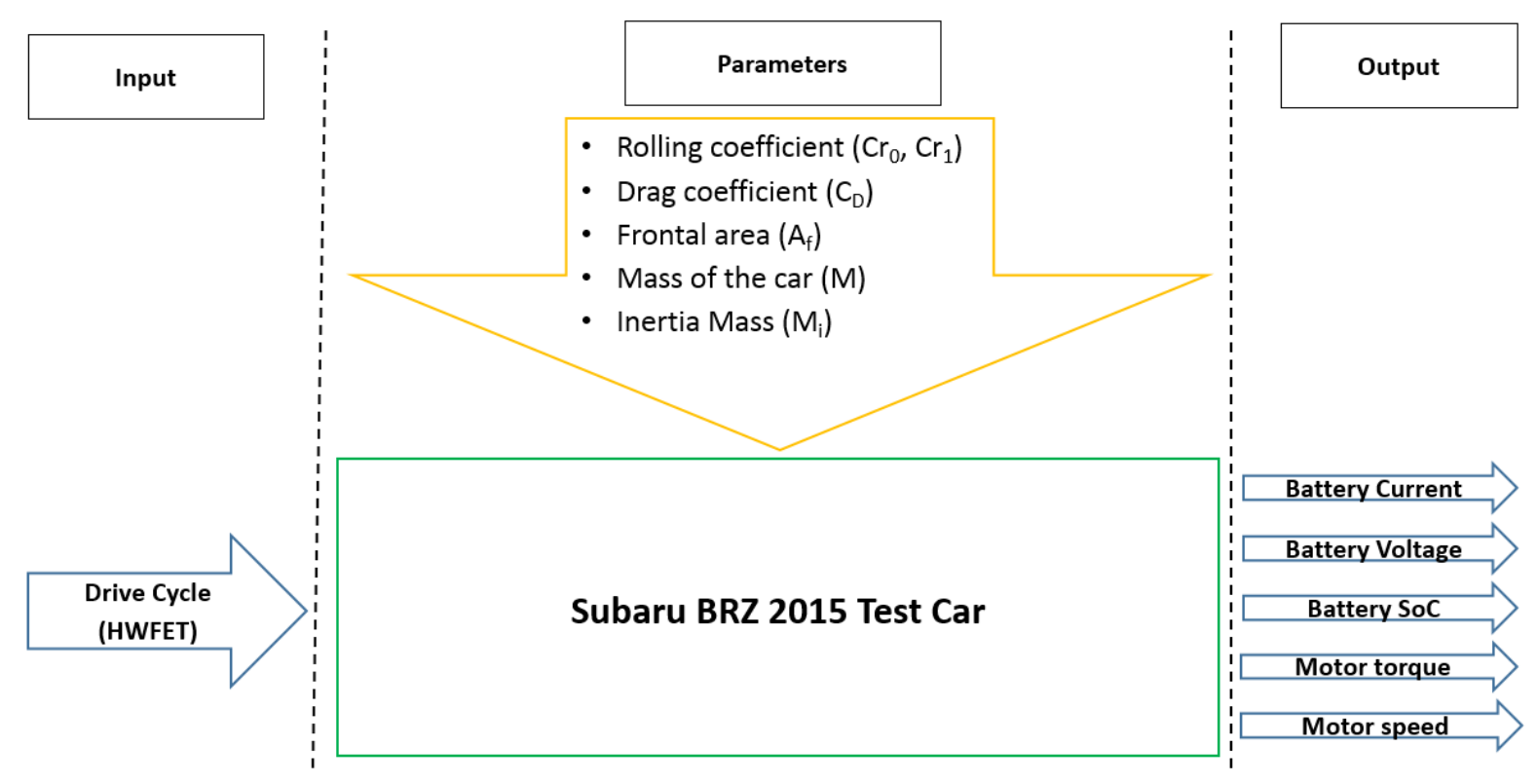

Figure 7. Dynamometer testing on the Subaru BRZ 2015.

\subsection{Electric Motor}

During the test, the speed of the car was controlled by a human driver operating an accelerator and brake pedal. The driver tried to follow the HWFET drive cycle as closely as possible. However, pedal sensitivity limitation and driver reactivity cause some inaccuracy that might explain the peaks in error between experimental and simulated motor speed and torque. This is why the vehicle speed profile during this experiment was recorded and used as an input for the simulation.

The goal of those preliminary results is to check the accuracy of the vehicle dynamics and electric motor models, described in Appendix A. In fact, a poor design would prevent the evaluation of the performance of the high-fidelity battery model. However, results in Figures 8 and 9 show high accuracy of the vehicle dynamics and motor models with a low average absolute error for the motor speed and good precision for the motor torque (see Table 3 ).

Table 3. Result of the experimental and simulated motor comparison.

\begin{tabular}{ccc}
\hline Electric Motor & Average Absolute Error & Standard Deviation Absolute Error \\
\hline Speed & 18 RPM & 37 RPM \\
\hline Torque & 4.4 N.m & $4.3 \mathrm{~N} . \mathrm{m}$ \\
\hline
\end{tabular}



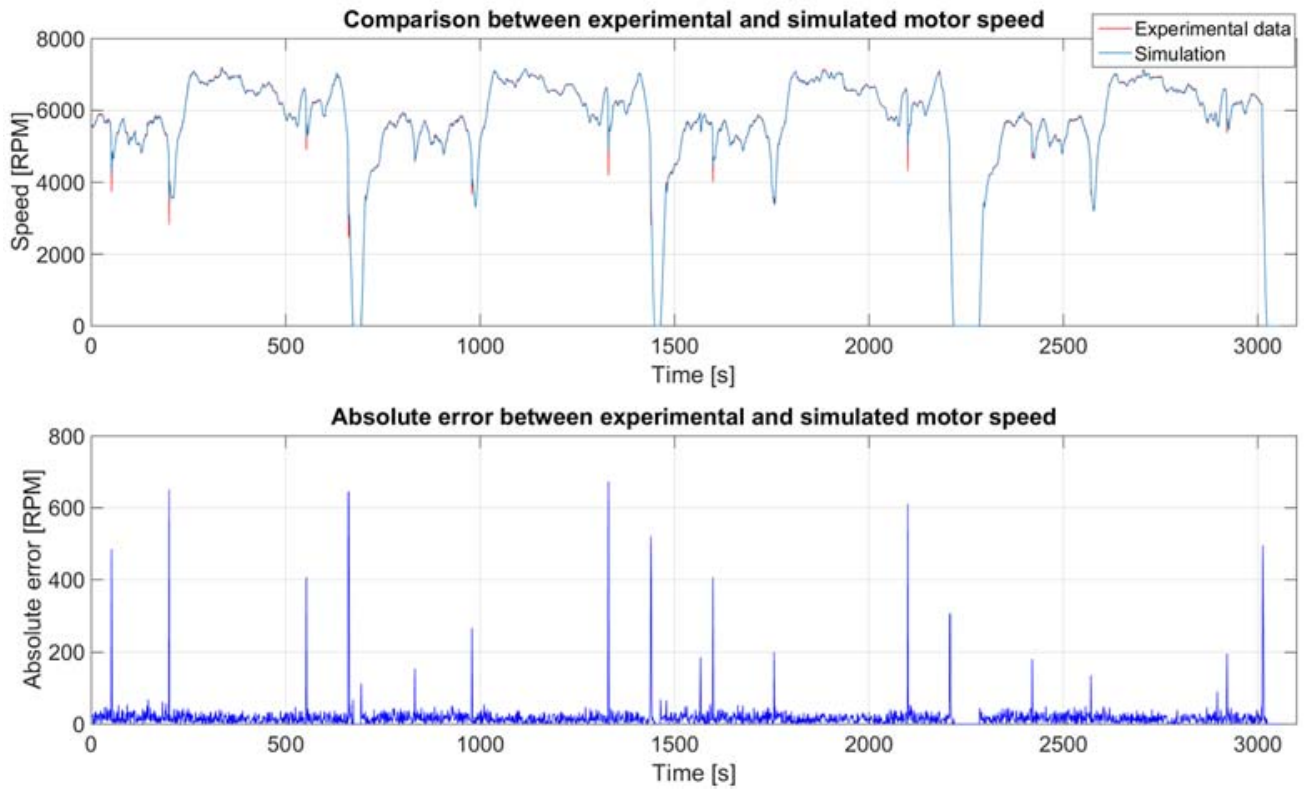

Figure 8. Motor speed comparison between experimental and simulated data.
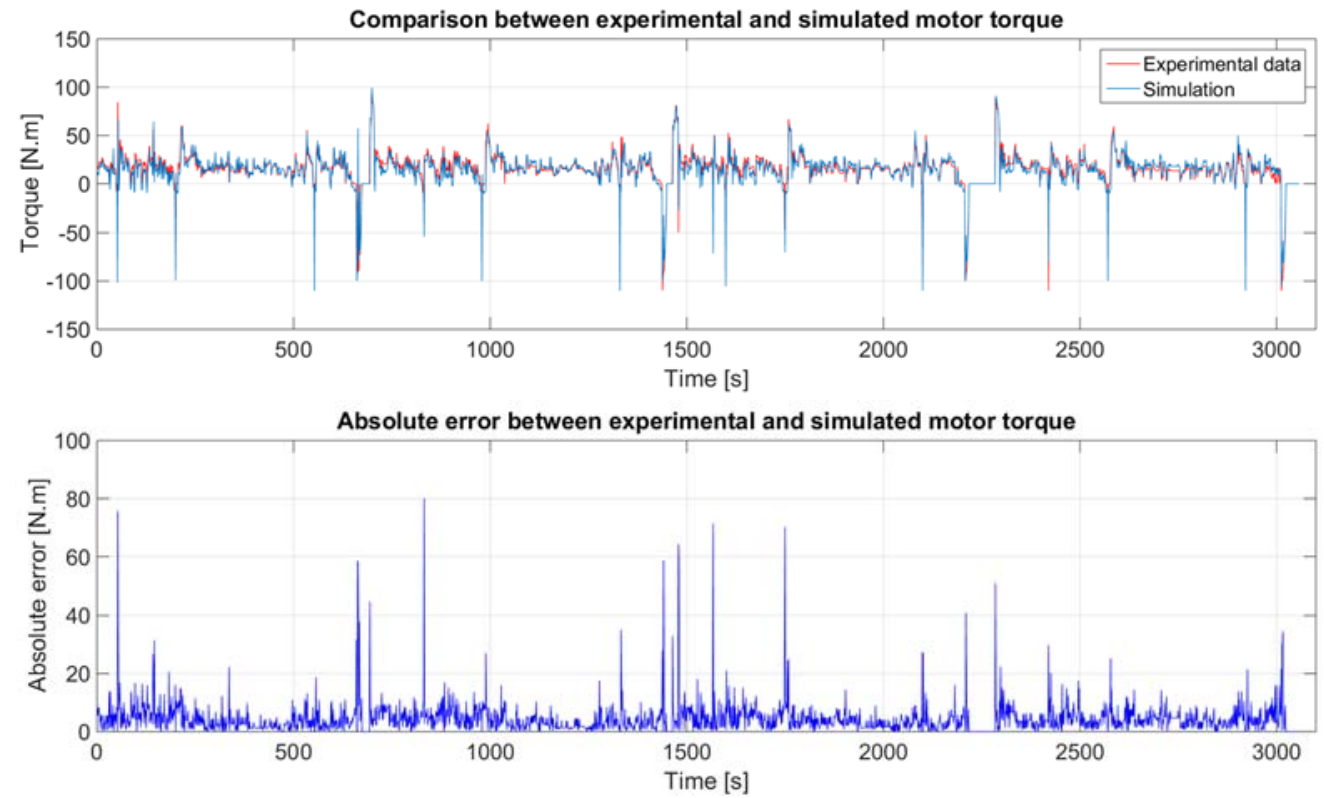

Figure 9. Motor torque comparison between experimental and simulated data.

\subsection{Battery}

The results of those experiments show that the recursive algorithm does not bring any additional precision to the battery model compared to the two RC network battery model by itself. Nevertheless, they do prove that the two RC network battery model improves the accuracy of the estimation of the voltage and $S o C$ of the battery, as shown in Figures 10 and 11 and Tables 4 and 5, compared to the simple internal resistance battery model. However, the impact of the battery model on the current is minimal, as shown in Figure 12 and Table 6. Those observations have a theoretical explanation. We know that $I_{\text {batt }}=P_{\text {batt }} / V_{\text {batt }}$. As $V_{\text {batt }}$ fluctuations are small compared to $P_{\text {batt }}, I_{\text {batt }}$ mainly depends on $P_{\text {batt }}$. In a high-level abstraction, we could say that $I_{\text {batt }}=\mathrm{f}\left(P_{\text {batt }}\right)$ as $V_{\text {batt }}$ is quite constant. This is why precision of the battery model will not have much effect on $I_{\text {batt }}$. We can also deduce that error on 
$I_{\text {batt }}$ mainly depends on the vehicle dynamics and electric motor models because $P_{\text {batt }}$ clearly depends on those equations (see Equations (1), (2) and (A1)-(A16)). However, the precision of the battery model will have an impact on $V_{\text {batt }}$. Indeed, this battery model is made to simulate the battery response voltage due to current changes. This is why $V_{\text {batt }}$ is influenced by the model. Concerning the $S o C$, it is computed by integrating $I_{\text {batt }}$. Even if the battery model has a locally small impact on $I_{\text {batt }}$, there is a difference between both calculated currents (see Table 5). By integrating those differences, the error, regarding the $\mathrm{SoC}$ estimation, accumulates. This explains why the $\mathrm{SoC}$ of the two RC network and the internal resistance battery model are slowly diverging from each other while discharging, as shown in Figure 12.

Table 4. Result of the experimental and simulated battery voltage comparison.

\begin{tabular}{cccc}
\hline Battery Model & $\begin{array}{c}\text { Average } \\
\text { Absolute Error }\end{array}$ & $\begin{array}{c}\text { Improvement } \\
\text { Factor }\end{array}$ & $\begin{array}{c}\text { Standard Deviation } \\
\text { Absolute Error }\end{array}$ \\
\hline Internal resistance & $8.0 \mathrm{~V}$ & - & $8.0 \mathrm{~V}$ \\
Two RC network recursive & $2.5 \mathrm{~V}$ & 3.200 & $2.8 \mathrm{~V}$ \\
Two RC network simple & $2.5 \mathrm{~V}$ & 3.200 & $2.7 \mathrm{~V}$ \\
\hline
\end{tabular}
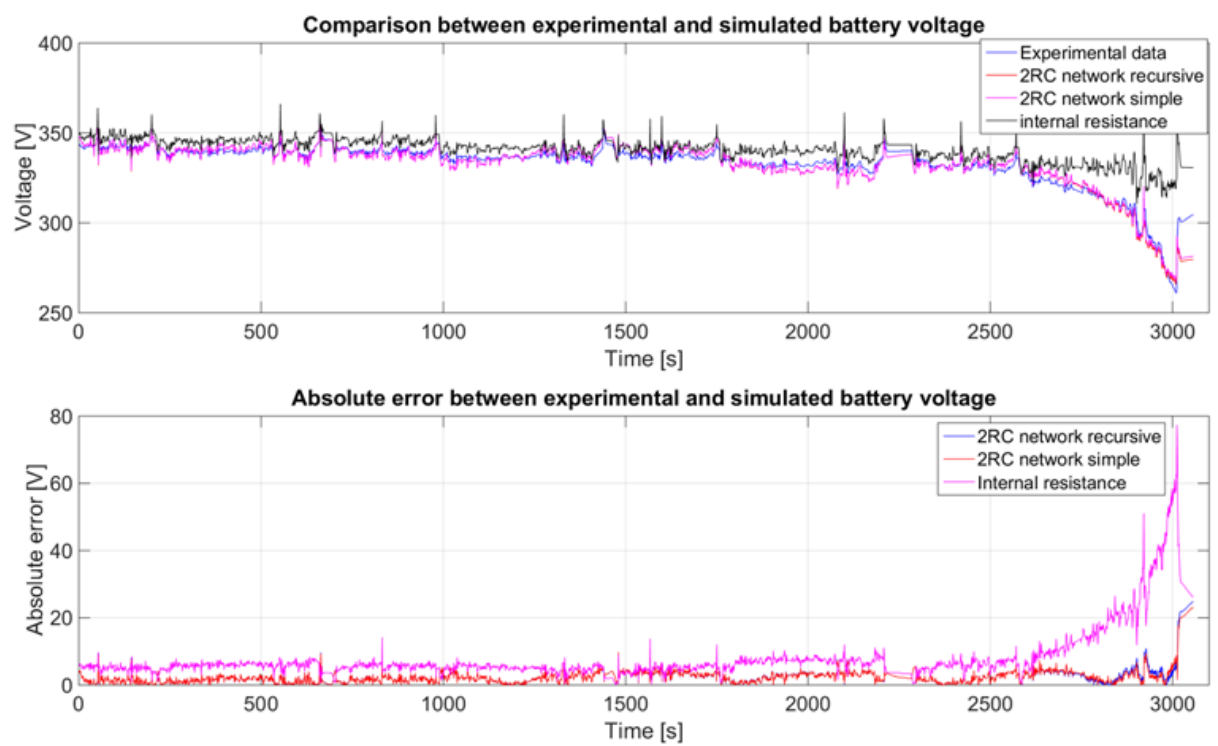

Figure 10. Battery voltage comparison between the experimental and simulated battery model.
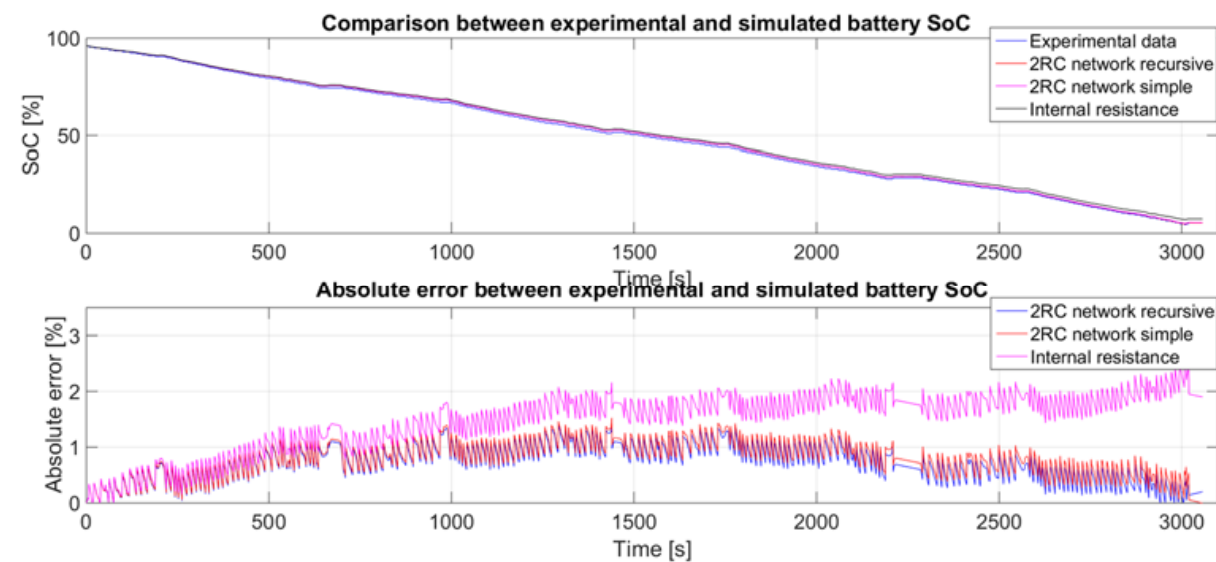

Figure 11. SoC comparison between the experimental and simulated battery model. 

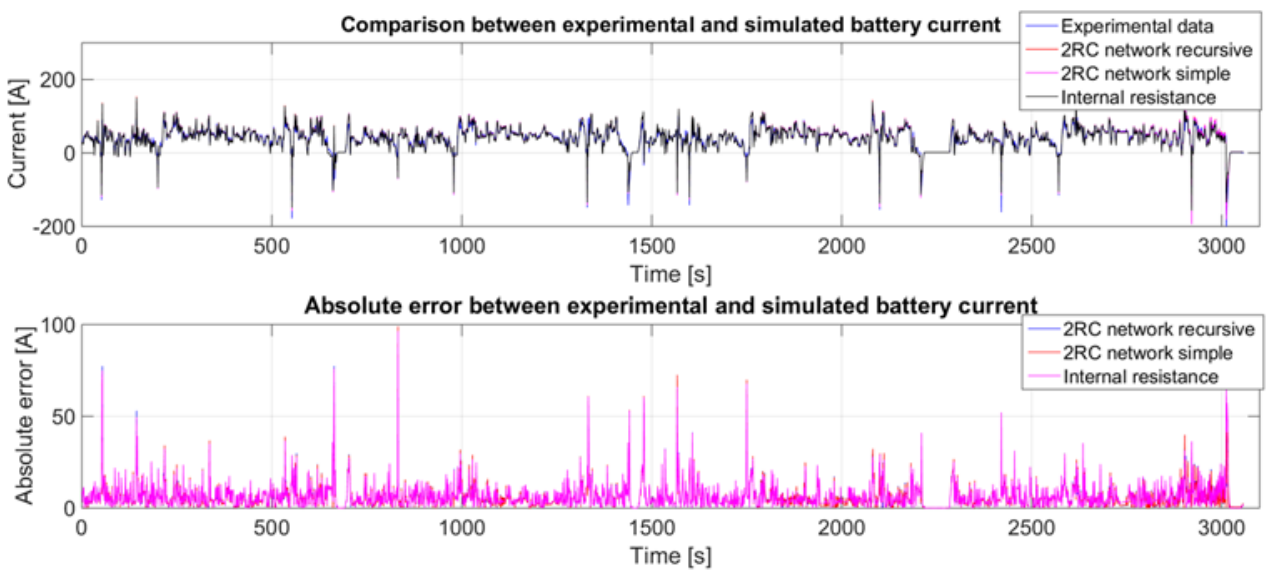

Figure 12. Battery current comparison between the experimental and simulated battery model.

Table 5. Result of the experimental and simulated battery SoC comparison.

\begin{tabular}{cccc}
\hline Battery Model & $\begin{array}{c}\text { Average } \\
\text { Absolute Error }\end{array}$ & $\begin{array}{c}\text { Improvement } \\
\text { Factor }\end{array}$ & $\begin{array}{c}\text { Standard Deviation } \\
\text { Absolute Error }\end{array}$ \\
\hline Internal resistance & $1.5 \%$ & - & $0.5 \%$ \\
Two RC network recursive & $0.7 \%$ & 2.142 & $0.3 \%$ \\
Two RC network simple & $0.8 \%$ & 1.875 & $0.3 \%$ \\
\hline
\end{tabular}

Table 6. Result of the experimental and simulated battery current comparison.

\begin{tabular}{cccc}
\hline Battery Model & $\begin{array}{c}\text { Average } \\
\text { Absolute Error }\end{array}$ & $\begin{array}{c}\text { Improvement } \\
\text { Factor }\end{array}$ & $\begin{array}{c}\text { Standard Deviation } \\
\text { Absolute Error }\end{array}$ \\
\hline Internal resistance & $6.3 \mathrm{~A}$ & - & $7.0 \mathrm{~A}$ \\
Two RC network recursive & $6.2 \mathrm{~A}$ & 1.016 & $7.0 \mathrm{~A}$ \\
Two RC network simple & $6.2 \mathrm{~A}$ & 1.016 & $6.9 \mathrm{~A}$ \\
\hline
\end{tabular}

For experimental data, $V_{\mathrm{OC}}$ has not been measured during the test. However, as the $V_{\mathrm{OC}}$ used with the two RC Network battery model is originally derived from experimental data (see Figure 5), the same $V_{\mathrm{OC}}$ has been used for computing the battery loss in experimental data. The results, shown in Figures 13 and 14 and Table 7, prove that the simulated losses from the two RC Network battery model are closer to reality than the one simulated by the internal resistance battery model. This observation suggests that the improvement of the battery accuracy may impact the MPC controller. Indeed, as the simulated battery power loss is closer to reality, the power requested to the engine will change and be closer to the real need of the vehicle. Besides, it is noted that the two RC network battery model estimates the bus voltage better. Therefore, when this model is used for the battery in the power-train model of a MPC algorithm, the variables such as voltage, current, torque, and speed of other components, such as engine, generator, and traction motor, will change. Thus, it can be predicted that, in a power-train model of a MPC where a two RC network battery model is deployed, a better estimation of actual variables of the system can be accomplished.

Table 7. Result of the experimental and simulated battery power loss comparison.

\begin{tabular}{cccc}
\hline Battery Model & $\begin{array}{c}\text { Average } \\
\text { Absolute Error }\end{array}$ & $\begin{array}{c}\text { Improvement } \\
\text { Factor }\end{array}$ & $\begin{array}{c}\text { Standard Deviation } \\
\text { Absolute Error }\end{array}$ \\
\hline Internal resistance & $325.9 \mathrm{~W}$ & - & $231.5 \mathrm{~W}$ \\
Two RC network recursive & $153.6 \mathrm{~W}$ & 2.122 & $181.9 \mathrm{~W}$ \\
Two RC network simple & $152.5 \mathrm{~W}$ & 2.137 & $178.4 \mathrm{~W}$ \\
\hline
\end{tabular}



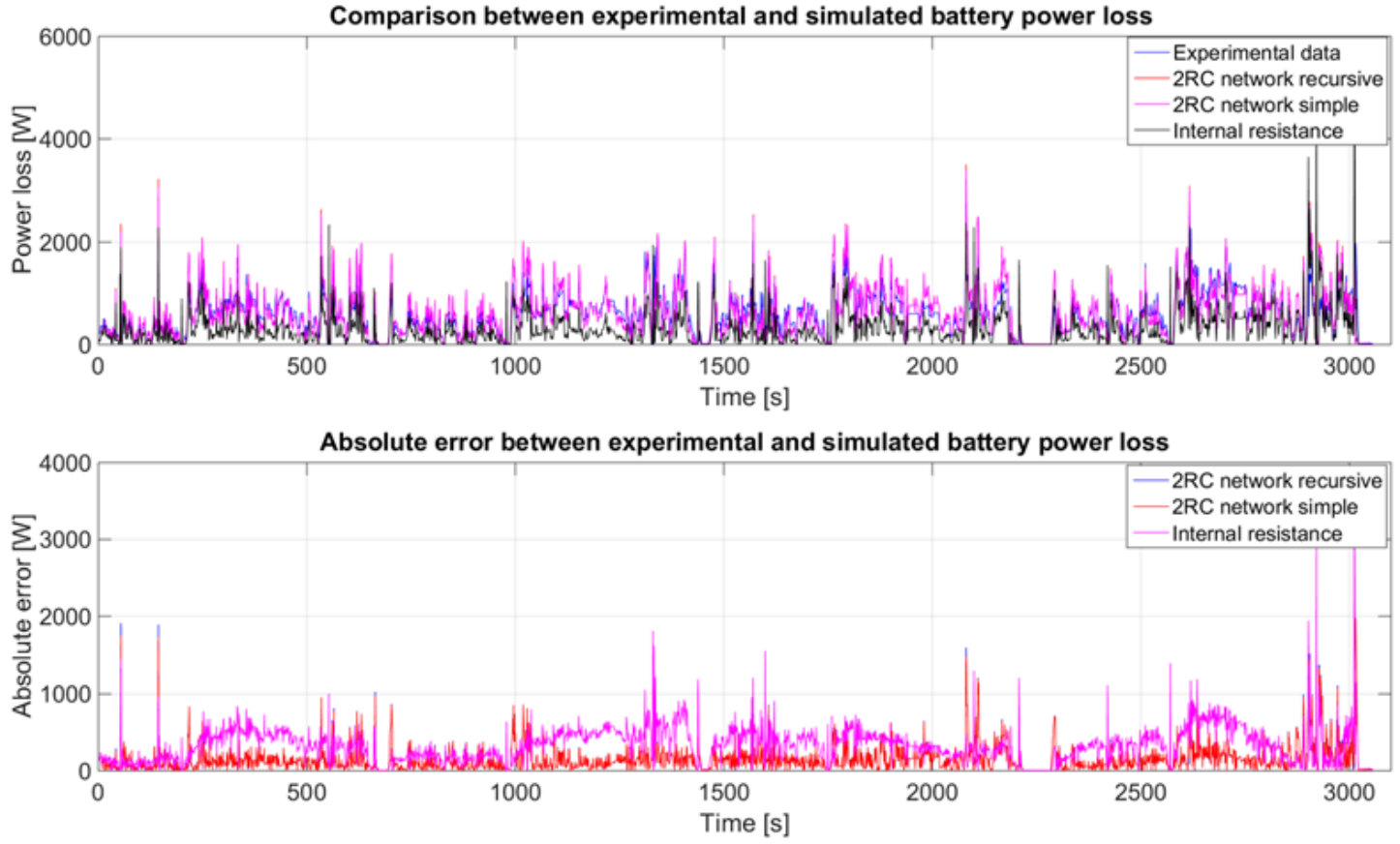

Figure 13. Power loss comparison between the experimental data and simulated battery model.

The employed method to compute both battery power and cumulative losses is described by Equations (16) and (17):

$$
\begin{gathered}
P b_{\text {loss }}=|| I_{\text {batt }}(t) \times V_{\text {batt }}(t)|-| I_{\text {batt }}(t) \times V \text { oc }(t)|| \\
E b_{\text {loss }}=\int_{0}^{T} \frac{\| I(t) \times V(t)|-| I(t) \times V \text { oc }(t)||}{3600} \mathrm{~d} t
\end{gathered}
$$

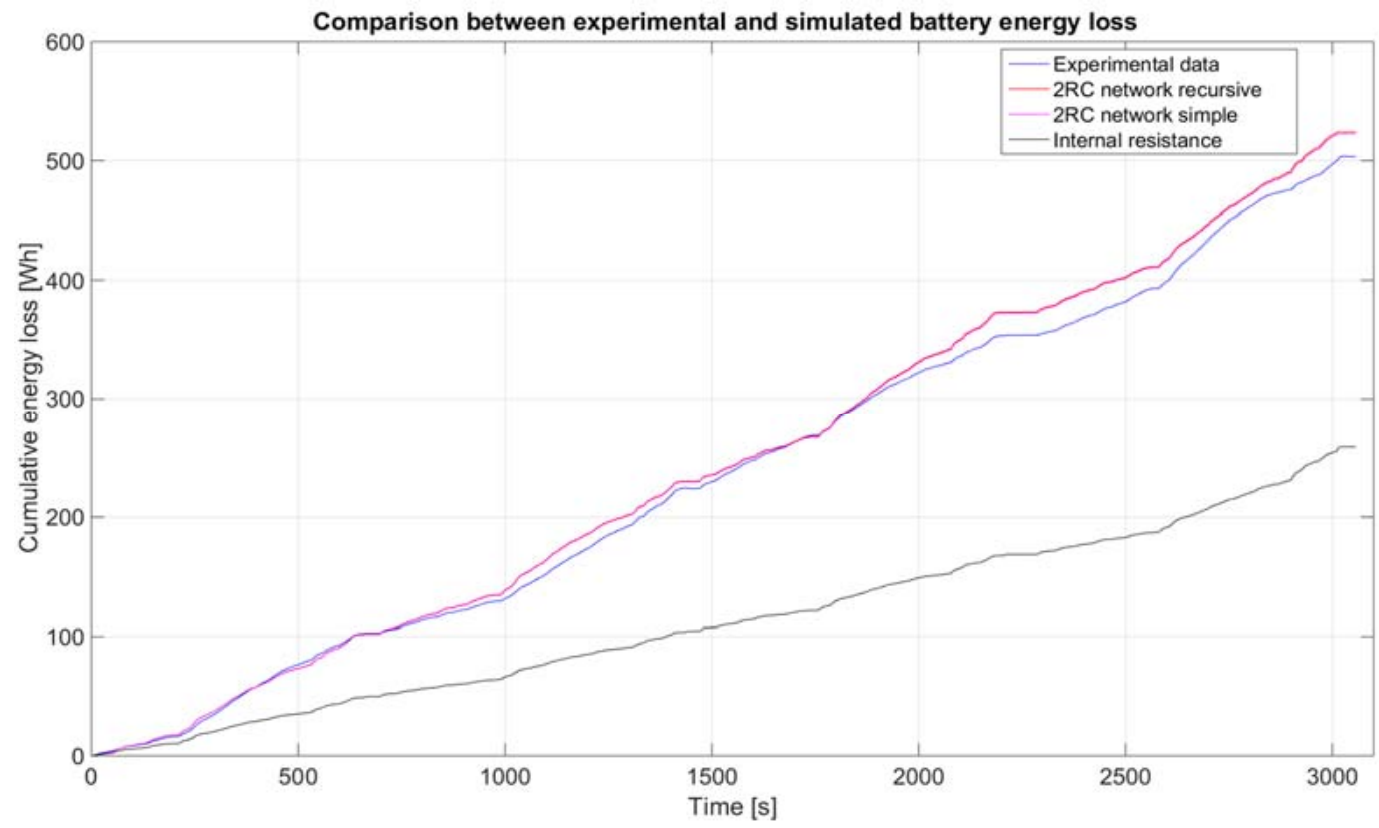

Figure 14. Cumulative energy loss comparison between the experimental data and simulated battery model. 


\section{Conclusions}

In this manuscript, a Matlab-based model has been developed with a high accuracy battery model for a hybridized Subaru BRZ 2015. This manuscript has two contributions. The first contribution is the development, for the first time in the field of a MPC controller, of a high accuracy battery for a PHEV Matlab-based model. Indeed, the new battery model reduces the absolute voltage, SoC and battery power loss error respectively by a factor of 3.2, 1.9 and 2.1 on average compared to the simpler battery model. Those observations highly infer that the performance of MPC will be impacted by the improvement of the high-fidelity battery model. It is likely that the high-fidelity battery model helps to reach more accurate estimation of the behaviors of other power-train components, and thus helps MPC to manage more precisely fuel consumption, battery lifetime, vehicle efficiency, or any other implemented cost function. However, there is no concrete proof that the improvement of the battery model fidelity is necessary to obtain an optimal control solution from the MPC. This is why the second contribution is the question raised in this manuscript: what is the optimal battery model fidelity required to optimize the performance of a MPC controller in the case of automotive application? To answer this question, the first sensitivity analysis of the battery model for MPC is planned to be conducted in a separate work. Following the control loop of Figure 15, this analysis should provide a procedure and results to determine the optimal tradeoff between the complexity and accuracy of the battery model of a PHEV for a MPC controller.

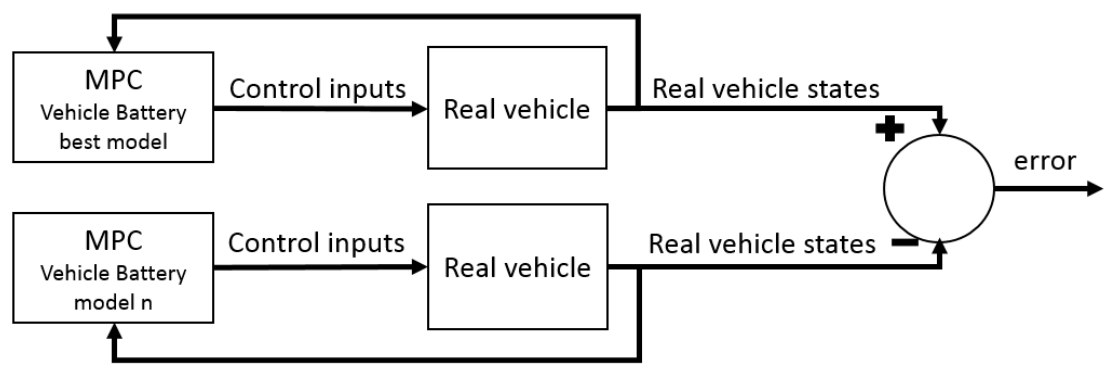

Figure 15. Control loop for the future sensitivity analysis.

Acknowledgments: The authors wish to thank the Center for Advanced Vehicular System (CAVS) and Matthew Doude and Car of the Future Team (COFT) for giving access to the resources and materials enabling to perform the experiments.

Author Contributions: Nicolas Sockeel wrote the manuscript and performed the experiment with William Meadows. Masood Shahverdi analyzed experimental results and edited the manuscript with Michael Mazzola.

Conflicts of Interest: The authors declare no conflict of interest.

\section{Nomenclature}

$\begin{array}{lll}\text { Symbol } & \text { Name } & \text { Units } \\ t & \text { The discrete time } & \mathrm{s} \\ \Delta t & \text { The step time } & \mathrm{s} \\ F_{\mathrm{r}} & \text { The rolling resistance } & \mathrm{N} \\ F_{\mathrm{g}} & \text { The grading resistance } & \mathrm{N} \\ F_{\mathrm{W}} & \text { The aerodynamic drag resistance } & \mathrm{N} \\ F_{\mathrm{a}} & \text { The acceleration resistance } & \mathrm{N} \\ F_{\mathrm{c}} & \text { The sum of every resistant force applied to the car } & \mathrm{N} \\ \beta & \text { The lateral angle between the wind and car direction } & \text { rads } \\ \vartheta & \text { The vertical angle between the wind and car direction } & \text { rads } \\ \alpha & \text { The road elevation } & \text { rads }\end{array}$


$P_{\mathrm{b}} \quad$ The power provided/received by the battery W

$P_{\mathrm{m} \_ \text {elec }} \quad$ The electric power requested/supply by the electric motor W

$P_{\text {g_elec }} \quad$ The power provide by the generator $\quad$ W

$P_{\mathrm{a}} \quad$ The constant power consumed by the auxiliary electric system $\quad$ W

$P_{\text {batt }} \quad$ The power provided/received by the battery W

$\begin{array}{lll}P_{\mathrm{c}} & \text { The power requested/provided by the car W }\end{array}$

$P_{\mathrm{m} \_ \text {mech }} \quad$ The power provided by the motor W

$v_{\mathrm{C}} \quad$ The car speed $\mathrm{m} / \mathrm{s}$

$v_{\mathrm{fw}} \quad$ The frontal wind speed $\mathrm{m} / \mathrm{s}$

$v_{\mathrm{w}} \quad$ The wind speed $\mathrm{m} / \mathrm{s}$

$\dot{v}_{c} \quad$ The car acceleration $\mathrm{m} / \mathrm{s}^{2}$

g The earth gravitational constant $\mathrm{m} / \mathrm{s}^{2}$

$\omega_{\mathrm{m}} \quad$ The motor speed $\mathrm{rads} / \mathrm{s}$

$\omega_{\mathrm{g}} \quad$ The generator speed rads $/ \mathrm{s}$

$\omega_{\mathrm{e}} \quad$ The engine speed $\mathrm{rads} / \mathrm{s}$

$\begin{array}{lll}T_{\mathrm{g}} & \text { The generator torque N.m }\end{array}$

$\begin{array}{lll}T_{\mathrm{e}} & \text { The engine torque N.m }\end{array}$

$T_{\mathrm{m}} \quad$ The motor torque N.m

$J_{\text {flwhl }} \quad$ The sum of the engine and generator flywheel moment of inertia $\mathrm{kg} / \mathrm{m}^{2}$

$\begin{array}{lll}M_{\mathrm{i}} & \text { The inertia mass due to all rotating parts } \mathrm{kg}\end{array}$

$M \quad$ The car mass $\quad \mathrm{kg}$

$\eta_{\text {batt }} \quad$ The battery efficiency -

$\eta_{\mathrm{g}} \quad$ The generator efficiency -

融ar $\quad$ The motor gear ratio efficiency -

$\eta_{\mathrm{m}} \quad$ The motor efficiency -

$\eta_{\mathrm{e}} \quad$ The engine efficiency -

$V_{\text {batt }} \quad$ The battery voltage $\quad$ V

$V_{\text {OC }} \quad$ The battery open circuit voltage V

$V_{\text {Transient_S }} \quad$ The battery short time response voltage $\quad$ V

$V_{\text {Transient_L }} \quad$ The battery long time response voltage $\quad \mathrm{V}$

I batt $\quad$ The current provided/received by the battery A

SoC The battery state of charge -

$C_{\text {batt }}$ The battery nominal capacity Ah

Q The battery capacity fades $\quad$ -

$P b_{\text {loss }} \quad$ The battery power loss $\quad$ W

$\triangle S o C \quad$ The cumulative $S o C$ variation for a given C-rate -

DOD The depth of discharge -

$n_{\text {cycle }} \quad$ The number of battery cycle -

$C_{\mathrm{r} 0} \quad$ The car static rolling coefficient -

$C_{\mathrm{r} 1} \quad$ The car dynamic rolling coefficient -

$C_{\mathrm{D}} \quad$ The car drag coefficient -

$\varepsilon_{0} \quad$ The gear reduction

$\begin{array}{lll}r d & \text { The wheels radius } & \mathrm{m}\end{array}$

$\begin{array}{lll}A_{\mathrm{f}} & \text { The car front size surface } & \mathrm{m}^{2} \\ \rho_{\mathrm{a}} & \text { The air density } & \mathrm{kg} / \mathrm{m}^{3}\end{array}$

$T_{\text {ext }} \quad$ The ambient absolute temperature $\quad \mathrm{K}$

$\begin{array}{lll}P_{\mathrm{r}} & \text { The ambient pressure } & \mathrm{Pa}\end{array}$

$\mathrm{R}_{\text {air }} \quad$ The specific gas constant for dry air $\quad \mathrm{J} /(\mathrm{kg} \cdot \mathrm{K})$
$\mathrm{R}$

$\begin{array}{lll}\mathrm{R} & \text { The perfect gas constant } \mathrm{J} / \mathrm{mol} \cdot \mathrm{K}\end{array}$

$\begin{array}{lll}E_{\mathrm{a}} & \text { The activation energy } & \mathrm{J} / \mathrm{mol}\end{array}$

$z \quad$ The power law factor -

$B \quad$ The pre-exponent factor 


\section{Appendix A.}

\section{Appendix A.1. Vehicle Dynamics}

This section describes the vehicle dynamic equations [36-39]. The power that the car's power-train has to provide can be computed as follows:

$$
P_{\mathrm{c}}(t)=\left[F_{\mathrm{r}}(t)+F_{\mathrm{g}}(t)+F_{\mathrm{W}}(t)+F_{\mathrm{a}}(t)\right] v_{\mathrm{c}}(t)
$$

The rolling resistance of the vehicle is defined by Equation (A2):

$$
F_{\mathrm{r}}(t)=\left(C_{\mathrm{r} 0}+C_{\mathrm{r} 1} \times\left[\frac{v_{\mathrm{c}}(t)}{44.44}\right]^{1.2}\right) M g \cos (\alpha(t))
$$

The static and dynamic rolling coefficients have been experimentally determined.

The grading resistance of the vehicle is defined by Equation (A3):

$$
F_{\mathrm{g}}(t)=M g \sin (\alpha(t))
$$

The aerodynamics drag resistance is defined as follows:

$$
\begin{gathered}
F_{\mathrm{W}}(\mathrm{t})=0.5 \rho_{\mathrm{a}}(t) \times A_{\mathrm{f}} \times C_{\mathrm{D}} \times\left(v_{\mathrm{c}}(t)-v_{\mathrm{fW}}(t)\right)^{2} \\
v_{\mathrm{fw}}(t)=v_{\mathrm{W}}(t) \cos (\beta(t)) \cos (\vartheta(t)) \\
\rho_{\mathrm{a}}(t)=\frac{P_{\mathrm{r}}}{R_{\mathrm{air}} T_{\mathrm{ext}}}
\end{gathered}
$$

The acceleration resistance of the vehicle is defined by Equation (A7):

$$
F_{\mathrm{a}}(t)=\left[M+M_{\mathrm{i}}\right] \dot{v}_{\mathrm{c}}(t)
$$

Appendix A.2. Electric Motor

The electric motor power demand at the wheels can be calculated by Equations (A8) and (A9):

$$
P_{\mathrm{m} \_ \text {mech }}(t)= \begin{cases}\frac{P_{\mathrm{c}}(t)}{\eta_{\text {gear }}}, & \text { if } P_{\mathrm{c}}(t) \geq 0 \\ P_{\mathrm{c}}(t) \eta_{\text {gear }}, & \text { if } P_{\mathrm{c}}(t)<0\end{cases}
$$

The motor speed and torque are computed by Equations (A10) and (A11):

$$
\begin{gathered}
\omega_{\mathrm{m}}(t)=\frac{v_{\mathrm{c}}(t) \varepsilon_{0}}{\mathrm{rd}} \\
T_{\mathrm{m}}(t)=\frac{P_{\mathrm{m}_{\mathrm{mech}}}(t)}{\omega_{\mathrm{m}}(t)}
\end{gathered}
$$

The electric power requested by the electric motor is computed as follows:

$$
P_{\mathrm{m} \_ \text {elec }}(t)= \begin{cases}\frac{\omega_{\mathrm{m}}(t) T_{\mathrm{m}}(t)}{\eta_{\mathrm{m}}\left(\omega_{\mathrm{m}}, T_{\mathrm{m}}\right)}, & \text { if } \mathrm{P}_{\mathrm{m} \_ \text {mech }}(\mathrm{t}) \geq 0 \\ \omega_{\mathrm{m}}(t) T_{\mathrm{m}}(t) \eta_{\mathrm{m}}\left(\omega_{\mathrm{m}}, T_{\mathrm{m}}\right) \eta_{\text {inv }}, & \text { if } P_{\mathrm{m} \_ \text {mech }}(\mathrm{t})<0\end{cases}
$$

The motor efficiency $\eta_{\mathrm{m}}$ is computed by interpolating the manufacturer look-up table over torque and speed.

\section{Appendix A.3. Electric Generator}

The electric power generated by the electric generator can be computed as follows:

$$
\begin{gathered}
P_{\text {g_elec }}(t)=T_{\mathrm{g}}(t) \omega_{\mathrm{g}}(t) \eta_{\mathrm{g}}\left(\omega_{\mathrm{g}}, T_{\mathrm{g}}\right) \\
\omega_{\mathrm{g}}(t)=\omega_{\mathrm{e}}(t)
\end{gathered}
$$


The generator efficiency $\eta_{\mathrm{g}}$ is calculated by interpolating the manufacturer look-up table over torque and speed.

\section{Appendix A.4. Engine}

The speed of the engine is already known as it is controlled by the MPC. Only the engine torque needs to be computed. In a discrete domain, the engine torque can be computed by Equation (A16):

$$
T_{\mathrm{e}}(t+1)=J_{\mathrm{flwhl}} \frac{\omega_{\mathrm{e}}(t+1)-\omega_{\mathrm{e}}(t)}{\Delta t}+T_{\mathrm{g}}(t+1)
$$

The fuel consumption is then computed by interpolating the manufacturer look-up table over engine torque and speed.

\section{References}

1. Shahverdi, M.; Mazzola, M.S.; Grice, Q.; Doude, M. Pareto Front of Energy Storage Size and Series HEV Fuel Economy Using Bandwidth-Based Control Strategy. IEEE Trans. Transp. Electrification 2016, 2, 36-51. [CrossRef]

2. Shahverdi, M.; Mazzola, M.; Grice, Q.; Doude, M. Bandwidth-Based Control Strategy for a Series HEV with Light Energy Storage System. IEEE Trans. Veh. Technol. 2016, 66, 1040-1052. [CrossRef]

3. Ranjit, A. A Model-Based Holistic Power Management Framework: A Study on Shipboard Power Systems for Navy Applications. Ph.D. Thesis, Department of Electrical and Computer Engineering, Mississippi State University, Starkville, MS, USA, 15 August 2014.

4. Overall Objectives of Model Predictive Control. Course of University of California. Available online: https://chemengr.ucsb.edu/ ceweb/faculty/seborg/teaching/SEM_2_slides/Chapter_20\%203-6-05.pdf (accessed on 19 March 2017).

5. Qin, S.J.; Thomas, A.B. A survey of industrial model predictive control technology. Control Eng. Pract. 2003, 11, 733-764. [CrossRef]

6. Malikopoulos, A. Supervisory power management control algorithms for hybrid electric vehicles: A survey. IEEE Trans. Intell. Transp. Syst. 2014, 15, 1869-1885. [CrossRef]

7. Kermani, S.; Delprat, S.; Guerra, T.M.; Trigui, R. Predictive Control for HEV Energy Management: Experimental Results. In Proceedings of the IEEE Vehicle Power and Propulsion Conference (VPPC), Dearborn, MI, USA, 7-11 September 2009.

8. Yu, K.; Xu, X.; Liang, Q.; Hu, Z.; Yang, J.; Guo, Y.; Zhang, H. Model Predictive Control for Connected Hybrid Electric Vehicle. Math. Probl. Eng. 2015, 2015. [CrossRef]

9. Shahverdi, M.; Mazzola, M.; Abdelwahed, S.; Doude, M.; Zhu, D. MPC-based power management system for a plug-in hybrid electric vehicle for relaxing battery cycling. In Proceedings of the IEEE Transportation Electrification Conference and Expo (ITEC), Chicago, IL, USA, 27-29 June 2016.

10. Di Cairano, S.; Liang, W.; Kolmanovsky, I.V.; Kuang, M.L.; Phillips, A.M. Power smoothing energy management and its application to a series hybrid powertrain. IEEE Trans. Control Syst. Technol. 2013, 21, 2091-2103. [CrossRef]

11. Patil, R.M.; Filipi, Z.; Fathy, H.K. Comparison of Supervisory Control Strategies for Series Plug-In Hybrid Electric Vehicle Powertrains through Dynamic Programming. IEEE Trans. Control Syst. Technol. 2014, 22, 502-509. [CrossRef]

12. Yan, F.; Wang, J.; Huang, K. Hybrid electric vehicle model predictive control torque-split strategy incorporating engine transient characteristics. IEEE Trans. Veh. Technol. 2012, 61, 2458-2467. [CrossRef]

13. Patil, R.M.; Kelly, J.C.; Filipi, Z.; Fathy, H.K. A Framework for the Integrated Optimization of Charging and Power Management in Plug-in Hybrid Electric Vehicles. IEEE Trans. Veh. Technol. 2013, 62, 2402-2412. [CrossRef]

14. Malikopoulos, A.A.; Smith, D.E. An optimization model for plug-in hybrid electric vehicles. In Proceedings of the ASME Internal Combustion Engine Division Fall Technical Conference, Morgantown, WV, USA, 2-5 October 2011.

15. Wang, Y.; Boyd, S. Fast model predictive control using online optimization. IEEE Trans. Control Syst. Technol. 2010, 18, 267-278. [CrossRef] 
16. Di Cairano, S.; Bernardini, D.; Bemporad, A.; Kolmanovsky, I.V. Stochastic MPC with Learning for Driver-Predictive Vehicle Control and its Application to HEV Energy Management. IEEE Trans. Control Syst. Technol. 2014, 22, 1018-1031. [CrossRef]

17. Olia, K.; Shahverdi, M.; Mazzola, M.; Sherif, A. Developing a Model Predictive Control-Based Algorithm for Energy Management System of the Catenary-Based Electric Truck. In Proceedings of the SAE International Powertrains, Fuels \& Lubricants Meeting, Baltimore, MD, USA, 24-26 October 2016.

18. Borhan, H.; Vahidi, A.; Phillips, A.; Kuang, M.; Kolmanovsky, I. Predictive energy management of a power-split hybrid electric vehicle. In Proceedings of the IEEE American Control Conference (ACC), St. Louis, MO, USA, 10-12 June 2009.

19. Santucci, A.; Sorniotti, A.; Lekakou, C. Power split strategies for hybrid energy storage systems for vehicular applications. J. Power Sources 2014, 258, 395-407. [CrossRef]

20. Borhan, H.; Vahidi, A. Model predictive control of a power-split Hybrid Electric Vehicle with combined battery and ultracapacitor energy storage. In Proceedings of the IEEE American Control Conference (ACC), Baltimore, MD, USA, 30 June-2 July 2010.

21. Borhan, H.; Zhang, C.; Vahidi, A.; Phillip, A.; Kuang, M.; Di Cairano, S. Nonlinear Model Predictive Control for power-split Hybrid Electric Vehicles. In Proceedings of the IEEE Conference on Decision and Control (CDC), Atlanta, GA, USA, 15-17 December 2010.

22. Santucci, A.; Sorniotti, A.; Lekakou, C. Model Predictive Control for the Power-Split between Supercapacitor and Battery for Automotive Applications. In Proceedings of the IEEE International Electric Vehicle Conference (IEVC), Santa Clara, CA, USA, 23-25 October 2013.

23. Liu, C.; Liu, L. Optimal Power Source Sizing of Fuel Cell Hybrid Vehicles based on Pontryagin's Minimum Principle. Int. J. Hydrog. Energy 2015, 40, 8454-8464. [CrossRef]

24. Liu, C.; Liu, L. PMP-Based Fuel Cell Hybrid Vehicle Power Management Considering Battery Current Constraint and Battery Health Analysis. In Proceedings of the SAE World Congress \& Exhibition, Detroit, MI, USA, 21-23 April 2015.

25. IDC Technologies: Industrial Automation; The IDC Engineers \& Ventus Publishing ApS: Frederiksberg, Danemark, 2012.

26. Plett, G.L. Extended Kalman filtering for battery management systems of LiPB-based HEV battery packs: Part 2. Modeling and identification. J. Power Source 2004, 134, 262-276. [CrossRef]

27. Plett, G.L. Extended Kalman filtering for battery management systems of LiPB-based HEV battery packs: Part 3. State and parameter estimation. J. Power Source 2004, 134, 277-292. [CrossRef]

28. Mazzola, M.S.; Shahverdi, M. Li-Ion Battery Pack and Applications. In Rechargeable Batteries; Springer: New York, NY, USA, 2015; pp. 455-476.

29. Shahverdi, M.; Mazzola, M.; Doude, M.; Grice, Q. A hybrid electric vehicle with minimal energy storage system. In Proceedings of the IEEE Transportation Electrification Conference and Expo (ITEC), Dearborn, MI, USA, 15-18 June 2014.

30. Einhorn, M.; Conte, F.V.; Kral, C.; Fleig, J. Comparison, Selection, and Parameterization of Electrical Battery Models for Automotive Applications. IEEE Trans. Power Electron. 2013, 28, 1429-1437. [CrossRef]

31. He, H.; Xiong, R.; Fan, J. Evaluation of Lithium-Ion Battery Equivalent Circuit Model for State of Charge Estimation by an Experimental Approach. Energies 2011, 4, 582-598. [CrossRef]

32. Chen, M.; Rincon-Mora, G.A. Accurate Electrical Battery Model Capable of Predicting Runtime and I-V Performance. IEEE Trans. Energy Convers. 2006, 21, 504-511. [CrossRef]

33. Li, J.; Mazzola, M.S. Accurate battery pack modeling for automotive applications. J. Power Sources 2013, 237, 215-228. [CrossRef]

34. Wang, J.; Liu, P.; Hicks-Garner, J.; Sherman, E.; Soukiazian, S.; Verbrugge, M.; Tataria, H.; Musser, J.; Finamore, P. Cycle-life model for graphite-LifePO 4 cells. J. Power Sources 2010, 196, 3942-3948. [CrossRef]

35. Ebbesen, S.; Elbert, P.; Guzzella, L. Battery state-of-health perceptive energy management of hybrid electric vehicles. IEEE Trans. Veh. Technol. 2012, 61, 2893-2900. [CrossRef]

36. National Programme on Technology Enhanced Learning (NPTEL), Electrical Engineering. Introduction to Hybrid and Electric Vehicles; Module 2: Dynamics of Electric and Hybrid vehicles; Lecture 3: Motion and Dynamic Equations for Vehicles. Available online: http://nptel.ac.in/courses/108103009/download/M2. pdf (accessed on 19 March 2017). 
37. Motevalli, V. EcoCar2: Plug-into the future. In Introduction to Hybrid-Electric Vehicles; Advanced Vehicle Technology Competition (AVTC) of Purdue University: West Lafayette, IN, USA, 2013.

38. Thogersen, M.L. Modeling of the Variation of Air Density with Altitude through Pressure, Humidity, and Temperature; EMD International A/S: Aalborg, Denmark, 2005.

39. Muench, S. Vehicle Dynamics. CEE Course. December 2016. Available online: www.courses.washington. edu/cee320w/lectures/Vehicle\%20Dynamics.ppt (accessed on 19 March 2017).

(C) 2017 by the authors. Licensee MDPI, Basel, Switzerland. This article is an open access article distributed under the terms and conditions of the Creative Commons Attribution (CC BY) license (http:/ / creativecommons.org/licenses/by/4.0/). 